\title{
Green Synthesis of High Quantum Yield Carbon Dots from Phenylalanine and Citric Acid: Role of Stoichiometry and Nitrogen Doping
}

Submitted to:

ACS Sustainable Chemistry \& Engineering

Shawninder Chahal ${ }^{\dagger}$, Nariman Yousefi ${ }^{\dagger}$, and Nathalie Tufenkji ${ }^{\dagger *}$

†Department of Chemical Engineering, McGill University, 3610 University St, Montréal, Québec H3A 0C5, Canada 


\section{Abstract}

Despite a growing interest in carbon dots (CDs), notably for their potential as a more

3 sustainable, less toxic alternative to inorganic quantum dots, the critical factors affecting their

4 physical, chemical, and optical properties are relatively unknown, limiting their widespread use.

5 Herein, a one-pot hydrothermal method was used to synthesize CDs from citric acid and

6 phenylalanine. CDs were synthesized over a range of reactant ratios; from pure citric acid to pure

7 phenylalanine and seven mixed ratios in between, achieving a quantum yield (QY) as high as $65 \%$

8 with a peak excitation/emission of $350 / 413 \mathrm{~nm}$. The goal was to determine the role of

9 stoichiometry on the chemical and structural composition of CDs, particularly its impact on

10 nitrogen doping, and in turn its effect on QY. We showed that a wide range of reactant ratios tend

11 towards reacting in a stoichiometric $2: 1$ molar ratio of phenylalanine to citric acid whereby the

12 resulting CDs have similar chemical composition and QY. Using this ratio may lead to a more

13 efficient and sustainable mass production process by reducing and reusing reactant waste. The QY

14 of the CDs was found to be more dependant on the oxygen-to-carbon ratio and the relative amount

15 of carboxyl oxygen in the $\mathrm{CD}$, than it was on the nitrogen-to-carbon ratio. The resulting $\mathrm{CDs}$ also

16 showed $\mathrm{Fe}^{3+}$ sensing capabilities through static fluorescence quenching with a limit of detection

17 of $3.5 \mu \mathrm{M}$. This study provides new insights which may be useful for the optimization of the green

18 synthesis of CDs for more widespread applications.

20 Keywords

21 Fluorescence, green chemistry, hydrothermal synthesis, nitrogen doping, regression

22 analysis, static quenching, quantum dots, nanomaterials. 


\section{Introduction}

Interest in carbon dots (CDs), a type of fluorescent carbon nanoparticle, has been steadily increasing since their discovery by $\mathrm{Xu}$ et al. ${ }^{1}$ One advantage of using CDs over traditional fluorescent dyes is that while dyes may experience considerable photobleaching after only a few seconds of photon excitation, some CDs can remain fluorescent for several hours while losing little to no fluorescence intensity. ${ }^{2-4} \mathrm{CD}$ synthesis methods such as hydrothermal, ${ }^{5}$ microwave, ${ }^{6}$ and dry heating (e.g. pyrolysis or calcination), ${ }^{7}$ can be made sustainable by using non-toxic, renewable, organic compounds found in Nature and consequently have often been shown to exhibit lower cytotoxicity than other quantum dots. ${ }^{8-11}$ This reduced cytotoxicity is best taken advantage of in the fields of bioimaging, ${ }^{12}$ drug delivery, ${ }^{13}$ and other forms of biomedical treatment. ${ }^{14}$ In addition to biological applications, CDs can also be used in chemical sensing, ${ }^{15}$ inks, ${ }^{16}$ films, ${ }^{17}$ lightemitting diodes, ${ }^{18}$ catalysts, ${ }^{19}$ and solar cells. ${ }^{20}$

Several bottom-up CD synthesis methods such as hydrothermal, ${ }^{5}$ microwave, ${ }^{6}$ and dry heating (e.g. pyrolysis or calcination), ${ }^{7}$ are popular in green CD synthesis since they are generally easy to implement, inexpensive, and can be performed as a one-pot synthesis. Citric acid is a common source of carbon in bottom-up CD synthesis, likely due to the presence of three carboxyl groups and a hydroxyl group allowing it to react with itself and other organic compounds. Citric acid can also be synthesized by the fungus Aspergillus niger, allowing for its production through bioprocesses. ${ }^{21}$ Fluorescence quantum yield (QY) is an important metric that quantifies the ability of a particle to release absorbed electromagnetic radiation as photons. A nitrogen doping agent is commonly added in the CD synthesis process, since it has been well documented that N-doped CDs have enhanced QY when compared to non-doped CDs. ${ }^{22}$ L-phenylalanine - a naturally occurring amino acid and one of the key components of the popular sweetener aspartame ${ }^{23,24}-$ 
contains a phenyl group, making it easier to produce graphene-like structures, and carboxyl and

47 amine groups, which can polymerize through addition-elimination reactions, making its chemical

48 structure advantageous for CD synthesis. It also contains nitrogen which can be used for doping

49 CDs to increase QY. Previously, Yang et al. performed a hydrothermal synthesis of CDs using

50 phenylalanine alone. ${ }^{25}$ Lijuan et al. performed pyrolysis of phenylalanine and citric acid to

51 synthesize graphene quantum dots for use in the anode material of lithium ion batteries. ${ }^{26}$ Shen

52 and Xia synthesized $\mathrm{CDs}$ hydrothermally from phenylalanine and $\mathrm{NaOH} .{ }^{27}$ Pandey et al. used

53 microwaves to synthesize $\mathrm{CDs}$ from phenylalanine, ethanol, and $\mathrm{NaOH}$ for the application of

54 haloperidol delivery. ${ }^{13}$ Wang et al. synthesized CDs hydrothermally from tryptophan,

55 phenylalanine, and $\mathrm{HCl}$ for the bioimaging of cancer cells and achieved a quantum yield of $21 \% .^{28}$

56 Significant knowledge gaps prevent CDs from replacing inorganic quantum dots in many

57 applications. For example, nitrogen doping is known to increase the QY of CDs by tuning their

58 electronic and surface properties, but the exact mechanism by which it does this is unknown. ${ }^{22}$

59 Moreover, there are many possible starting reagents that CDs may be synthesized from; however,

60 they lead to a range of properties and QYs. In this work, two types of CDs with the same atomic

61 ratio of nitrogen to carbon, but with remarkably different QYs, were synthesized with the intent of

62 gaining insight into the role of CD chemical composition and nitrogen doping on QY. We also

63 created an array of CDs, by varying the citric acid to phenylalanine reactant ratio, from which we

64 can determine the role of stoichiometry on the chemical composition of the synthesized CDs.

65 Gaining insight into the stoichiometry of CD synthesis and its impact on QY would help in the

66 development of more economical and sustainable synthesis routes, particularly for mass

67 production, by minimizing reactant waste. The synthesized CDs also displayed $\mathrm{Fe}^{3+}$ sensing

68 capabilities. 
Experimental

\section{Chemicals}

Citric acid, L-phenylalanine, quinine hemisulfate salt monohydrate, $\mathrm{AgNO}_{3}$, $\mathrm{HAuCl}_{4} \cdot 3 \mathrm{H}_{2} \mathrm{O}, \mathrm{BaCl}_{2} \cdot 2 \mathrm{H}_{2} \mathrm{O}, \mathrm{CaCl}_{2} \cdot 2 \mathrm{H}_{2} \mathrm{O}, \mathrm{CdCl}_{2}, \mathrm{CoCl}_{2} \cdot 6 \mathrm{H}_{2} \mathrm{O}, \mathrm{CsCl}, \mathrm{CuCl}_{2}, \mathrm{FeCl}_{3}, \mathrm{LiCl}, \mathrm{MgCl}_{2}$,

$74 \mathrm{MnCl}_{2} \cdot 4 \mathrm{H}_{2} \mathrm{O}, \mathrm{NaCl}, \mathrm{NaNO}_{3}, \mathrm{Pd}\left(\mathrm{CH}_{3} \mathrm{COO}\right)_{2}$, and $\mathrm{ZnCl}_{2}$ were purchased from Sigma-Aldrich.

$75 \mathrm{FeCl}_{2} \cdot 4 \mathrm{H}_{2} \mathrm{O}, \mathrm{HCl}, \mathrm{KCl}, \mathrm{KBr}, \mathrm{KI}, \mathrm{NaCH}_{3} \mathrm{COO} \cdot 3 \mathrm{H}_{2} \mathrm{O}, \mathrm{NaClO}_{4}$ were purchased from Thermo Fisher

76 Scientific. Sulfuric acid was purchased from VWR. Reverse osmosis water (produced from a Mar

77 Cor Purification reverse osmosis water purification unit) was used across all the experiments.

Synthesis of Carbon Dots

Citric acid (from 0 to $270 \mathrm{mM}$ ) and phenylalanine (from 0 to $180 \mathrm{mM}$ ) were dissolved in

$8115 \mathrm{~mL}$ of water and placed in a glass vial which was then placed in a Teflon-lined autoclave 82 chamber (Hydrion Scientific, $50 \mathrm{~mL}$ ) and heated to $200{ }^{\circ} \mathrm{C}$ for $8 \mathrm{~h}$. A complete list of synthesis

83 concentrations can be found in Table S1. The resulting suspension was left to cool naturally to 84 room temperature. The suspension was then filtered using a $0.1 \mu \mathrm{m}$ PVDF syringe filter unit 85 (Millex-VV, EMD Millipore) to remove any large particles. Approximately $10 \mathrm{~mL}$ of the sample 86 was then dialyzed in $1 \mathrm{~L}$ of water using a $3.5 \mathrm{kDa}$ molecular weight cut-off regenerated cellulose 87 membrane (Spectrum Labs) for $24 \mathrm{~h}$ with two changes of the dialysis water to remove any 88 unreacted citric acid and phenylalanine, as well as any small fluorophores that may have been 89 generated. CDs are named based on the phenylalanine mole percent in the reactants, e.g. $\mathrm{P}_{95}-\mathrm{CDs}$ 90 were made using $95 \mathrm{~mol} \%$ phenylalanine and $5 \mathrm{~mol} \%$ citric acid in water. A proposed mechanism 91 of the initial synthesis steps is shown in Scheme 1. 


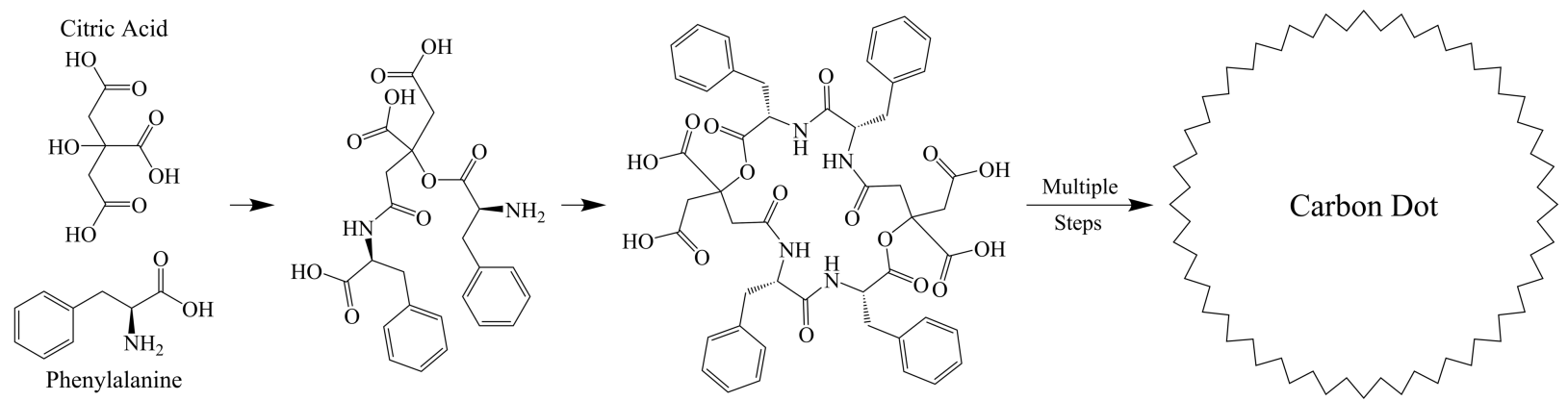

94 Scheme 1. Proposed mechanism of the initial synthesis steps for the reaction of citric acid and phenylalanine.

\section{Characterization}

Fluorescence measurements were performed using a Horiba FluoroMax-4. UV-Vis absorbance measurements were taken using a Thermo Fisher Scientific BioMate 3S UV-Visible

99 spectrophotometer. Fluorescence lifetime measurements were taken using a Horiba EasyLife X 100 (368 nm excitation). X-ray photoelectron spectroscopy (XPS) measurements were taken using a 101 Thermo Fisher Scientific K-Alpha X-Ray Photoelectron Spectrometer System. Fourier-transform 102 infrared (FTIR) spectroscopy measurements were performed using a PerkinElmer Spectrum Two 103 FTIR spectrometer with a single reflection diamond ATR. Atomic force microscopy (AFM) was 104 done in tapping mode using a Bruker MultiMode 8 AFM equipped with a Nanoscope V controller 105 using a Bruker ScanAsyst-air silicon nitride probe (nominal frequency: $70 \mathrm{kHz}$, spring constant: $1060.4 \mathrm{~N} / \mathrm{m}$, tip radius: $2 \mathrm{~nm}$ ). Transmission electron microscopy (TEM) images were obtained using an FEI Tecnai G2 F20 TEM located at the Facility for Electron Microscopy Research at McGill 108 University. Raman spectroscopy was performed using a Bruker SENTERRA II compact Raman 109 microscope with a He-Ne laser at a $532 \mathrm{~nm}$ wavelength. 


\section{Quantum Yield}

112 Quantum yields were measured using the relative approach reported by Williams et al. ${ }^{29}$

113 All samples had an absorbance of 0.1 or lower. Equation 1 was then used to determine the quantum

114 yield:

$$
\mathrm{QY}_{S}=\mathrm{QY}_{R} \frac{F_{S}}{F_{R}} \frac{A_{R}}{A_{S}} \frac{\eta_{S}^{2}}{\eta_{R}^{2}}
$$

116 where QY is the quantum yield, $F$ is the integral of the fluorescence emission scan, $A$ is the

117 absorbance, $\eta$ is the index of refraction of the solvent, $S$ denotes the type of sample to be analysed 118 (i.e. $\mathrm{CDs}$ ), and $R$ denotes the reference material. The reference material was quinine sulfate in 0.1

$119 \mathrm{M} \mathrm{H}_{2} \mathrm{SO}_{4}$, which has a QY of 54.6\% ${ }^{30}$ QY fluorescence measurements were performed using an 120 excitation and emission slit width of $1 \mathrm{~nm}$. An excitation wavelength of $350 \mathrm{~nm}$ was used unless 121 otherwise specified.

\section{Ion Sensing}

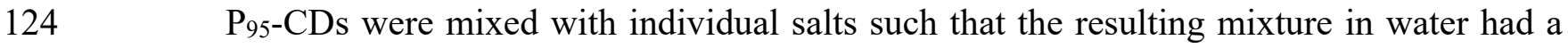
$125 \mathrm{CD}$ and ion concentration of $\sim 15 \mathrm{mg} \mathrm{L}^{-1}$ and $1000 \mu \mathrm{M}$, respectively. The mixture was then 126 incubated for $1 \mathrm{hr}$ at room temperature. An excitation wavelength of $350 \mathrm{~nm}$ was used, and the 127 fluorescence intensity was measured at an emission wavelength of $400 \mathrm{~nm}$.

128 A linear $\mathrm{Fe}^{3+}$ calibration curve was generated in a similar manner with slight variations. $129 \mathrm{P}_{95}$-CDs were mixed with $\mathrm{FeCl}_{3}$ such that the resulting mixture had a $\mathrm{CD}$ and $\mathrm{Fe}^{3+}$ concentration 130 of $\sim 140 \mathrm{mg} \mathrm{L}^{-1}$ and up to $50 \mu \mathrm{M}$, respectively. The mixture was then incubated for $1 \mathrm{hr}$ at room 131 temperature. An excitation wavelength of $350 \mathrm{~nm}$ was used, and fluorescence intensity was 
132 measured at an emission wavelength of $376 \mathrm{~nm}$, which provided the best limit of detection (LOD)

133 using Equation 2:31

134

$$
L O D=3.3\left(\frac{S_{y}}{S}\right)
$$

136 where $S_{y}$ is the standard deviation of the response of the linear calibration curve, and $S$ is the slope

137 of the linear regression.

138 All ion sensing fluorescence measurements were done using an excitation and emission slit 139 width of $2 \mathrm{~nm}$.

141 Statistical Analysis

142 Data is reported as the mean \pm 2 standard errors of the mean. Statistical significance was 143 measured using the Student's $t$-test, with $\mathrm{p}<0.05$ considered as significant. Comparisons made 144 between two types of CDs (e.g. $\mathrm{P}_{95}-\mathrm{CDs}$ vs $\left.\mathrm{P}_{100}-\mathrm{CDs}\right)$ were done using an unpaired homoscedastic $145 t$-test. Comparisons made on a $\mathrm{CD}$ before and after a treatment (e.g. addition of $\mathrm{Fe}^{3+}$ ) were done 146 using a paired $t$-test.

\section{Results and Discussion}

149 Nitrogen Doping and Quantum Yield

150 It has been argued that nitrogen doping of CDs can greatly increase their QY. ${ }^{22}$ Figure 1a

151 shows that the QY increased as the phenylalanine mole fraction $\left(x_{p}\right)$ in the reactants increased from 1520.00 to 0.95 . However, this is only true so long as citric acid is present, whereas using only 
153 phenylalanine $\left(x_{p}=1.00\right)$ in water results in a low QY. Interestingly, there is no significant 154 difference $(\mathrm{p}>0.05)$ between the $\mathrm{QY}$ of undoped $\mathrm{P}_{0}$-CDs $(2.0 \pm 0.9 \%)$ and $\mathrm{N}$-doped $\mathrm{P}_{100}$-CDs $155(3.4 \pm 2.5 \%)$ indicating that citric acid and phenylalanine create higher QY CDs when together than 156 either reactant alone. Citric acid plays two major roles in the synthesis of CDs. It contains three 157 carboxyl groups and one hydroxyl group which gives it several sites to react with phenylalanine 158 and other citric acid molecules. Citric acid also keeps the $\mathrm{pH}$ of the reacting mixture low which 159 acts as a catalyst for addition-elimination reactions such as Fischer esterification. ${ }^{32}$ Therefore, the 160 absence of citric acid in the $\mathrm{P}_{100-} \mathrm{CD}$ reaction may have caused those $\mathrm{CDs}$ to synthesize poorly and 161 could partially explain why the QY of $\mathrm{P}_{95}-\mathrm{CDs}(65 \pm 7.2 \%)$ is 19 times higher $(\mathrm{p}<0.01)$ than $\mathrm{P}_{100^{-}}$ 162 CDs $(3.4 \pm 2.5 \%)$. This places the QY of $\mathrm{P}_{95}-\mathrm{CDs}$ on the higher end of CDs synthesized using 163 renewable nitrogen doping agents, ${ }^{33-35}$ but on the lower end of those synthesized from synthetic 164 nitrogen doping agents. ${ }^{36-40}$ The post-dialysis $\mathrm{pH}$ of the suspensions of CDs synthesized from citric 165 acid (i.e. all the CDs except $\mathrm{P}_{100}$-CDs) ranges from 3.4-3.7, while the suspension of $\mathrm{P}_{100}$-CDs has $166 \mathrm{a} \mathrm{pH}$ of 4.6. To determine if this difference in $\mathrm{pH}$ could explain the vast difference in QY between $167 \mathrm{P}_{95}-\mathrm{CDs}$ and $\mathrm{P}_{100}-\mathrm{CDs}$, the post-dialysis $\mathrm{pH}$ of the $\mathrm{P}_{95}-\mathrm{CD}$ and $\mathrm{P}_{100}-\mathrm{CD}$ suspensions were adjusted 168 to 2.4 using $\mathrm{HCl}$; however, the $\mathrm{QY}$ of $\mathrm{P}_{95}-\mathrm{CDs}$ was still 11 times greater than that of $\mathrm{P}_{100}-\mathrm{CDs}$ 169 ( $\mathrm{p}<0.01)$, confirming that the post-dialysis $\mathrm{pH}$ is not the primary cause for the discrepancy in QY. 170 In addition, the $\mathrm{QY}$ remains mostly unchanged in $\mathrm{P}_{25}-\mathrm{CDs}, \mathrm{P}_{50}-\mathrm{CDs}$, and $\mathrm{P}_{75}-\mathrm{CDs}$, revealing that 171 continuously increasing the concentration of the nitrogen doping agent does not necessarily 172 increase the QY at the same rate. For instance, tripling $x_{p}$ from 0.25 to 0.75 only increases $(\mathrm{p}<0.05)$ 173 the QY from $49 \pm 1.1 \%$ to $52 \pm 1.6 \%$. 


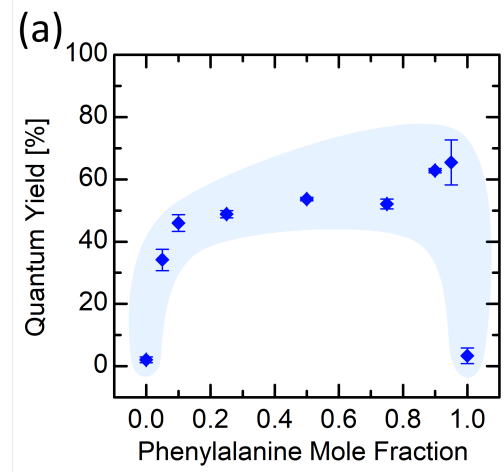

(b)

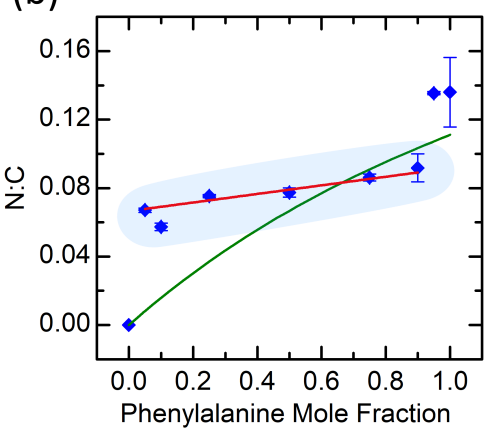

(c)

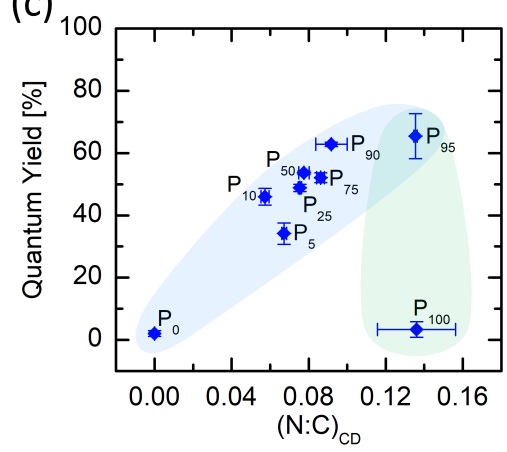

175

176

177

178

$$
(N: C)_{C D}=0.025 x_{p}+\frac{1}{15}
$$

Figure 1. (a) Quantum yield of CDs vs phenylalanine mole fraction (balance is citric acid) in water at an excitation wavelength of $350 \mathrm{~nm}$. (b) Nitrogen to carbon ratios for various phenylalanine mole fractions. Blue diamonds represent (N:C)CD. Green curved line represents $(\mathrm{N}: \mathrm{C})_{\mathrm{R}}$. Red line shows a linear trend for $0.05 \leq x_{p} \leq 0.90$. (c) Quantum Yield vs (N:C)CD as determined by XPS. Error bars represent 2 standard errors of the mean $(\mathrm{N}=3)$.

carbon atomic ratio in the CDs $\left((\mathrm{N}: \mathrm{C})_{\mathrm{CD}}\right)$, as determined using XPS, shows little change despite large changes in the nitrogen to carbon atomic ratio of the reactants $\left((\mathrm{N}: \mathrm{C})_{\mathrm{R}}\right)$ and $x_{p}$. Specifically, when $0.05 \leq x_{p} \leq 0.90,(\mathrm{~N}: \mathrm{C})_{\mathrm{CD}}$ follows the fitted function (Equation 3, red line in Figure 1b):

Figure $1 \mathrm{~b}$ shows that there is a linear trend for $0.05 \leq x_{p} \leq 0.90$, over which the nitrogen to 
$192 \frac{2}{3}$, and can be visualized by the intersection of the two functions in Figure $1 \mathrm{~b}$, indicating that a 2:1

193 molar ratio of phenylalanine to citric acid is the stoichiometric ratio. Oxygen and hydrogen are not

194 considered in this stoichiometry, since they may be added to and removed from the CD during 195 synthesis in the form of water molecules. These results show that the reaction tends to proceed at 196 a phenylalanine to citric acid molar ratio of $2: 1$ when $0.25 \leq x_{\mathrm{p}} \leq 0.75$, and $1: 1$ as $x_{\mathrm{p}}$ approaches 0 .

197 Figure 1c shows the relationship between the measured QY and $(\mathrm{N}: \mathrm{C})_{\mathrm{CD}}$. Over the range, $1980 \leq x_{\mathrm{p}} \leq 0.95$, the QY generally increases with $(\mathrm{N}: \mathrm{C})_{\mathrm{CD}}$. As mentioned previously, $\mathrm{P}_{25}-\mathrm{CDs}, \mathrm{P}_{50}-\mathrm{CDs}_{\text {, }}$ 199 and $\mathrm{P}_{75}-\mathrm{CDs}$ have similar QYs and $(\mathrm{N}: \mathrm{C})_{\mathrm{CD}}$, but their $x_{p}$, and in turn, $(\mathrm{N}: \mathrm{C})_{\mathrm{R}}$, varies considerably. 200 Figure 1c shows these three CDs clustered together despite covering a wide range of $x_{p}$. This 201 further supports the mechanism proposed previously; that having $0.25 \leq x_{\mathrm{p}} \leq 0.75$ during synthesis 202 does not change the composition or properties of the resulting CDs considerably and that 203 phenylalanine and citric acid will tend towards a stoichiometric ratio at $x_{\mathrm{p}}=\frac{2}{3}$. Conversely, there 204 is a great difference in QY between $\mathrm{P}_{95}-\mathrm{CDs}$ and $\mathrm{P}_{100}-\mathrm{CDs}$ despite having similar $(\mathrm{N}: \mathrm{C})_{\mathrm{CD}}$.

205 There is little work in the literature with specific focus on the role of nitrogen doping in 206 enhancing the QY of CDs, particularly with regards to stoichiometry. Permatasari et al. 207 synthesized graphene quantum dots from citric acid and urea. ${ }^{41}$ They reported that graphene 208 quantum dots with a larger ratio of pyridinic nitrogen to pyrrolic nitrogen exhibited more 209 fluorescence; however, the effect on QY was not measured. By examining the optical, chemical, 210 and physical properties of the CDs synthesized in this work, we hope to gain new insight into the 211 role of stoichiometry and nitrogen doping on QY. 


\section{Chemistry of CDs}

Analysis of the XPS spectra reveals peaks indicating the presence of carbon, nitrogen, and

215 oxygen at binding energies of $\sim 285 \mathrm{eV}, \sim 400 \mathrm{eV}$, and $\sim 532 \mathrm{eV}$, respectively. A charge correction

216 is applied, where needed, in the form of a binding energy region shift to account for any charge

217 accumulation. When considering only $\mathrm{C}, \mathrm{N}$, and $\mathrm{O}$, all the $\mathrm{CDs}$ have a composition of

218 approximately $50-70 \% \mathrm{C}, 0-10 \% \mathrm{~N}$, and $20-50 \% \mathrm{O}$ on an atomic basis (Table S2). A

219 representative example of the deconvolution of $\mathrm{C}_{1 \mathrm{~s}}, \mathrm{~N}_{1 \mathrm{~s}}$, and $\mathrm{O}_{1 \mathrm{~s}}$ peaks for $\mathrm{P}_{25}-\mathrm{CDs}, \mathrm{P}_{50}-\mathrm{CDs}$, and

$220 \mathrm{P}_{75}-\mathrm{CDs}$ is shown in Figure $\mathrm{S} 1$ and $\mathrm{P}_{95}-\mathrm{CDs}$ and $\mathrm{P}_{100}-\mathrm{CDs}$ is shown in Figure $\mathrm{S} 2$.

221 The $\mathrm{C}_{1 \mathrm{~s}}$ spectra is deconvoluted using five peaks representing $\mathrm{sp}^{2}(\sim 284.2 \mathrm{eV}),{ }^{42} \mathrm{sp}^{3}$

$(\sim 284.9 \mathrm{eV}),{ }^{43} \mathrm{C}-\mathrm{N} / \mathrm{C}-\mathrm{O}(\sim 286.0 \mathrm{eV}),{ }^{44,}{ }^{45} \mathrm{C}=\mathrm{N} / \mathrm{C}=\mathrm{O}(\sim 287.8 \mathrm{eV}),{ }^{46}$ and $\mathrm{O}-\mathrm{C}=\mathrm{O}(\sim 288.8 \mathrm{eV}){ }^{47}$

223 carbon. The $\mathrm{N}_{1 \text { s }}$ spectra is deconvoluted using three peaks representing $\mathrm{C}-\mathrm{NH}-\mathrm{C}\left(2^{\circ}\right.$ amine $)$ and/or

224 pyridinic $\mathrm{N}(\sim 399.6 \mathrm{eV}), \mathrm{C}-\mathrm{N}(\mathrm{C})-\mathrm{C} / \mathrm{N}-\mathrm{C}=\mathrm{O}\left(3^{\circ}\right.$ amine and/or amide) and/or pyrrolic $\mathrm{N}(\sim 400.4$

$225 \mathrm{eV})$, and $-\mathrm{NH}_{3}{ }^{+} /$graphitic $\mathrm{N}(\sim 401.6 \mathrm{eV}) .{ }^{48,} 49$ The $\mathrm{O}_{1 \mathrm{~s}}$ spectra is deconvoluted using four peaks

226 representing $\mathrm{COOH}(\sim 531.1 \mathrm{eV}), \mathrm{C}=\mathrm{O}(\sim 531.9 \mathrm{eV}), \mathrm{C}-\mathrm{O}(\sim 532.7 \mathrm{eV})$, and $\mathrm{C}-\mathrm{OH}(\sim 533.5 \mathrm{eV}) .{ }^{50}$

227 A detailed breakdown and analysis of the relative amounts of these bonds can be found in Table

228 S3 and the XPS Analysis section of the Supporting Information (SI).

229 The chemical similarity of $\mathrm{P}_{25}-\mathrm{CDs}, \mathrm{P}_{50}-\mathrm{CDs}$, and $\mathrm{P}_{75}-\mathrm{CDs}$ is evident in their FTIR spectra

230 (Figure 2a), which further indicates that there is little difference between these CDs. A comparison

231 of the FTIR spectra of $\mathrm{P}_{95}$-CDs and $\mathrm{P}_{100}-\mathrm{CDs}$ (Figure $2 \mathrm{~b}$ ) shows four regions of interest. Regions

232 1-3 are considerably more pronounced in $\mathrm{P}_{95}-\mathrm{CDs} . \mathrm{P}_{95}-\mathrm{CDs}$ and $\mathrm{P}_{100}-\mathrm{CDs}$ both show a prominent

233 peak in Region 4, i.e. $1260-890 \mathrm{~cm}^{-1}$, with prominence at $1084 \mathrm{~cm}^{-1}$ originating from $\mathrm{C}-\mathrm{N}$ and

$234 \mathrm{C}-\mathrm{O}$ stretching, indicating the presence of amines and alkoxy groups. Only this last region has

235 similar prominence among $\mathrm{P}_{95}-\mathrm{CDs}$ and $\mathrm{P}_{100}-\mathrm{CDs}$, but when considered relative to the magnitude 
236 of the other peaks (Figure S3), $\mathrm{P}_{100}$-CDs appear to have a greater relative amount of the bonds

237 associated with this peak (i.e. $\mathrm{C}-\mathrm{N} / \mathrm{C}-\mathrm{O}$ ) than $\mathrm{P}_{95}-\mathrm{CDs}$, which is consistent with the results from

238 XPS (Table S3). A detailed analysis can be found in the FTIR Analysis section of the SI. Figure

239 S4 shows the FTIR spectra for all the synthesized CDs as well as the reactants, citric acid and 240 phenylalanine.

(a)

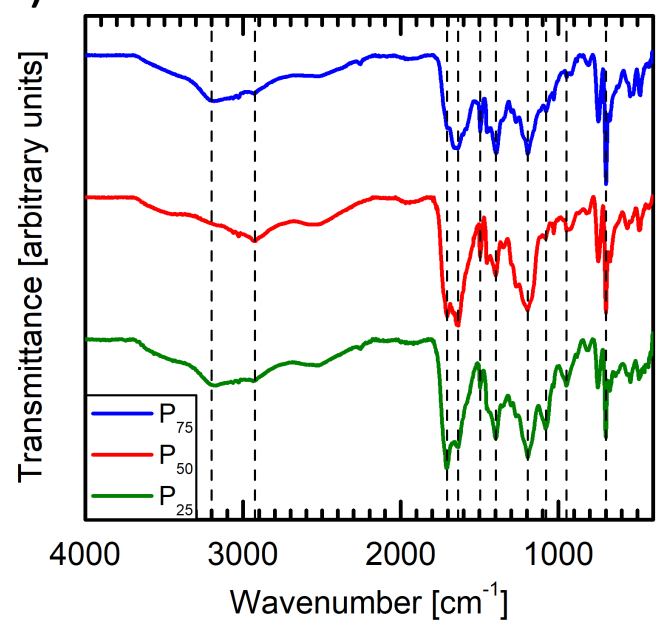

(b)

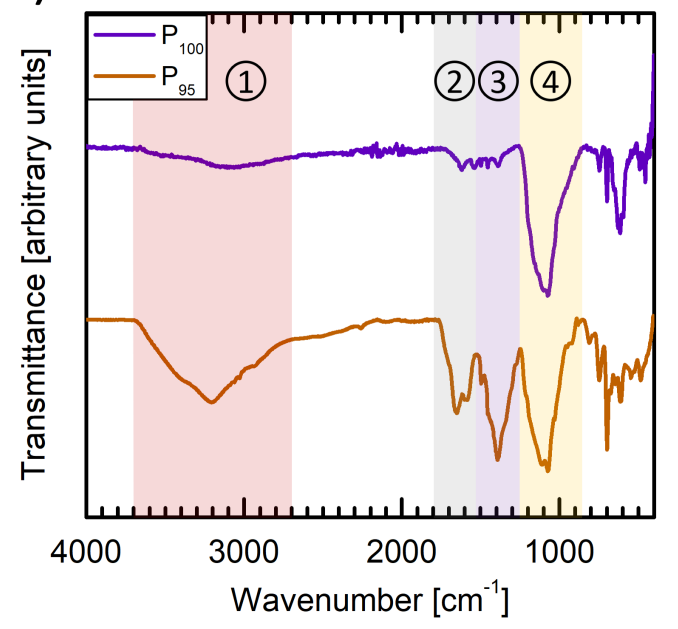

243 Figure 2. FTIR spectra of (a) $\mathbf{P}_{25}-\mathrm{CDs}, \mathbf{P}_{50}-\mathrm{CDs}$, and $\mathbf{P}_{75}-\mathrm{CDs}$ and (b) $\mathbf{P}_{95}-\mathrm{CDs}$ and $\mathbf{P}_{100}-\mathrm{CDs}$. Dashed lines in (a) 244 are to show alignment of peaks between CD types. Shaded regions in (b) are to highlight similarities and differences in certain regions. 
A shortcoming of FTIR and XPS analyses is that peaks can often be associated with more

248 than one type of bond. For instance, it is difficult to assess how much of the $\mathrm{N}$ is in the form of a 249 protonated amine $\left(-\mathrm{NH}_{3}{ }^{+}\right)$versus a graphitic form, since these two peaks are generally found at 250 the same location $(\sim 401.6 \mathrm{eV}) .{ }^{48,51}$ From FTIR, the strong presence of C-N, but minimal N-H in $251 \mathrm{P}_{100}-\mathrm{CDs}$ suggests that nitrogen is incorporated inside the CDs in the form of a tertiary amine, 252 pyridinic $\mathrm{N}$, or graphitic $\mathrm{N}$, as opposed to its presence on the surface as a primary or secondary 253 amine or a pyrrolic $\mathrm{N}$. This suggests that the increase in $-\mathrm{NH}_{3}{ }^{+}$/graphitic $\mathrm{N}$ in $\mathrm{P}_{100}-\mathrm{CDs}$ when 254 compared to $\mathrm{P}_{95}-\mathrm{CDs}$ could be due to an increase in graphitic $\mathrm{N}$, instead of $-\mathrm{NH}_{3}{ }^{+}$as this is 255 supported by the FTIR spectra for the two CDs. In general, there is agreement between the FTIR 256 and XPS analyses in terms of the types of bonds identified. Both techniques confirm that nitrogen 257 doping occurs and indicate the presence of $\mathrm{sp}^{2}$ and $\mathrm{sp}^{3}$ carbon, as well as the presence of alkoxy, 258 hydroxyl, carboxyl, and carbonyl groups.

259 The difference in QY between $\mathrm{P}_{95}-\mathrm{CD}$ and $\mathrm{P}_{100}-\mathrm{CD}$ s may be best explained by examining 260 the oxygen containing groups. Zhang et al. synthesized graphene quantum dots that were not 261 nitrogen-doped, and found that reducing them using $\mathrm{NaBH}_{4}$ increased their QY from $2.6 \%$ to $26210.1 \%{ }^{52}$ In this study, $\mathrm{P}_{95}-\mathrm{CDs}$ have $33 \%$ less $(\mathrm{p}<0.05)$ relative $\mathrm{COOH}$ oxygen and a $22 \%$ lower $263(\mathrm{p}<0.05)$ oxygen to carbon ratio $(\mathrm{O}: \mathrm{C})_{\mathrm{CD}}$ than $\mathrm{P}_{100}-\mathrm{CDs}$, indicating that $\mathrm{P}_{95}-\mathrm{CD}$ are overall more 264 reduced than $\mathrm{P}_{100}-\mathrm{CDs}$.

265 Furthermore, to illustrate the uniqueness of $\mathrm{P}_{100}-\mathrm{CDs}$ chemical composition relative to the 266 other CDs synthesized in this work, a principal component analysis (PCA) was performed on the 267 14-dimensional XPS data $\left(\right.$ i.e. $(\mathrm{N}: \mathrm{C})_{\mathrm{CD}},(\mathrm{O}: \mathrm{C})_{\mathrm{CD}}$, and the relative amount of each bond type in the $2685 \mathrm{C}_{\mathrm{s}}$ features, $3 \mathrm{~N}_{1 \mathrm{~s}}$ features, and $4 \mathrm{O}_{1 \mathrm{~s}}$ features) which captured $75 \%$ of the variance in two 
269 principal components (Figure S5). From the PCA plot, $\mathrm{P}_{0}-\mathrm{CDs}$ are distinct from the rest of the

$270 \mathrm{CDs}$, as expected, due to its lack of nitrogen. Interestingly, $\mathrm{P}_{100}-\mathrm{CDs}$ are shown to be overall, quite

271 dissimilar as well from the rest of the N-doped carbon dots. A multiple linear regression analysis

272 was performed, correlating the chemical composition of the CDs based on XPS spectra to the QY.

273 To determine the most important of the 14 features, we aimed to maximize the coefficient of

274 determination, $\mathrm{R}^{2}$, with the least number of features possible. Our analysis revealed that an $275 \mathrm{R}^{2}=0.934$ (Figure 3 ) was achievable using only 2 features, the $(\mathrm{O}: \mathrm{C})_{\mathrm{CD}}$ and the relative amount of $276 \mathrm{COOH}$ oxygen (from $\mathrm{O}_{1 \mathrm{~s}}$ spectra), in the form of Equation 4:

277

$$
Q Y=0.271-0.500 z_{1}-0.238 z_{2}-0.192 z_{1} z_{2}
$$

279 where $z_{1}$ and $z_{2}$ are the standard score of the $(\mathrm{O}: \mathrm{C})_{\mathrm{CD}}$ and the relative amount of $\mathrm{COOH}$ oxygen 280 (from $\mathrm{O}_{1 \mathrm{~s}}$ spectra), respectively.

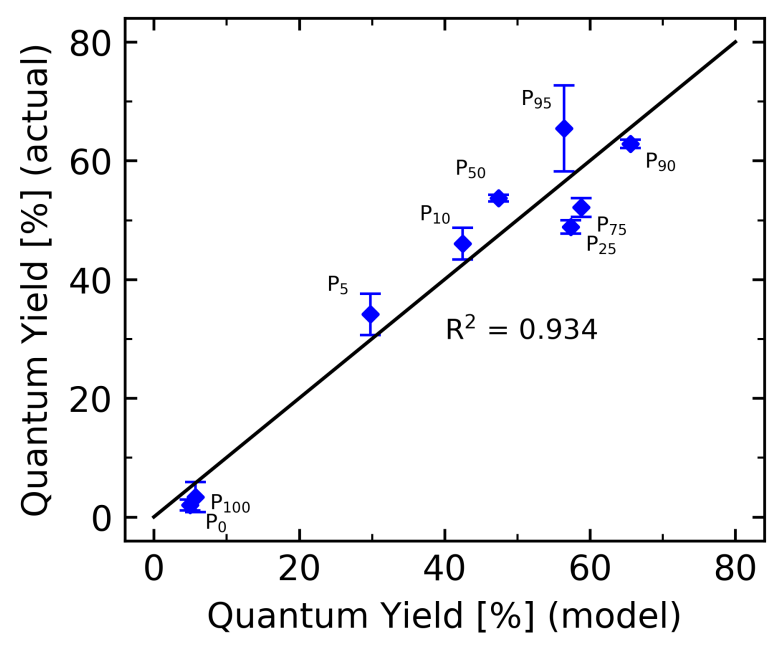

282 Figure 3. Comparison of the actual QY (blue diamonds) to the QY calculated from Equation 4 (black line). 
All of the coefficients in Equation 4 were negative, suggesting that an increase in either the

$285(\mathrm{O}: \mathrm{C})_{\mathrm{CD}}$ or the relative amount of $\mathrm{COOH}$ oxygen would decrease the quantum yield. The 286 interaction term suggests a compounding effect when the two features move in the same direction.

287 Interestingly, if we replace the interaction term with a $3^{\text {rd }}$ feature, the $(\mathrm{N}: \mathrm{C})_{\mathrm{CD}}$, the regression model 288 would only have an $\mathrm{R}^{2}=0.838$ (Table S4), suggesting that the role of nitrogen comes second to the 289 role of oxygen in determining the QY of this set of CDs. It is worth clarifying here that the purpose 290 of developing this multiple linear regression was to be qualitative, as opposed to quantitative. It is 291 entirely possible that the QY of a CD is dependant on features beyond the 14 features assessed 292 here from XPS, but we still consider it interesting that the $(\mathrm{O}: \mathrm{C})_{\mathrm{CD}}$ and the relative amount of 293 COOH oxygen on their own can account for a large portion of the variance observed in QY. The 294 parameters and $\mathrm{R}^{2}$-values of the different permutations of the features used to make the multiple 295 linear regression are found in Table S4. Similarly, the means and standard deviations of the 296 features considered are found in Table S5.

\section{Fluorescence and UV-Vis Spectroscopy}

Fluorescence and absorbance measurements were performed on CD suspensions in water.

300 In addition to being used to calculate the QY, the fluorescence data provides the peak excitation 301 and emission wavelengths for a $\mathrm{CD}$, while the absorbance data provides peak absorbance 302 wavelengths. Figure $4 \mathrm{a}, \mathrm{b}$ compares the fluorescence intensity of $\mathrm{P}_{95}-\mathrm{CDs}$ with $\mathrm{P}_{100}$-CDs. A clear

303 difference in the peak fluorescence between the two CDs is observed. $\mathrm{P}_{95}$-CDs display a peak 304 fluorescence at an excitation/emission wavelength of $350 / 413 \mathrm{~nm}$, while $\mathrm{P}_{100}$-CDs peak at $315 / 395$ $305 \mathrm{~nm}$. Although the fluorescence intensity of $\mathrm{P}_{100}-\mathrm{CDs}$ is higher when an excitation wavelength of $306315 \mathrm{~nm}$ is used, this is due to an increase in absorbance, and therefore the QY of the $\mathrm{P}_{100}-\mathrm{CDs}$ 
307 shows no significant difference $(\mathrm{p}>0.05)$ at an excitation wavelength of $315 \mathrm{~nm}$ when compared 308 to an excitation wavelength of $350 \mathrm{~nm}$. Therefore, the shift in the peak excitation and emission 309 wavelengths do not explain the difference in QY. Fluorescence heat maps for $\mathrm{P}_{25}-\mathrm{CDs}, \mathrm{P}_{50}-\mathrm{CDs}$, 310 and $\mathrm{P}_{75} \mathrm{CDs}$ (Figure $\mathrm{S} 6$ ) reveal that their peak intensities occur in the same general 311 excitation/emission region, specifically at, $345 / 402 \mathrm{~nm}, 345 / 408 \mathrm{~nm}$, and 350/421 nm,

312 respectively. The relatively circular appearances of the heat maps demonstrate that the emission 313 spectra of the CDs are not strongly dependant on their excitation wavelength in the regions 314 surrounding their peak excitation and emission wavelengths. For instance, over the excitation 315 range of 300-365 nm, $\mathrm{P}_{95}$-CD's peak emission occurs between 411-415 nm. Only excitation 316 wavelengths of $370-400 \mathrm{~nm}$ begin showing excitation-dependant emission; however, the 317 fluorescence intensity begins to weaken as well. 
(a)

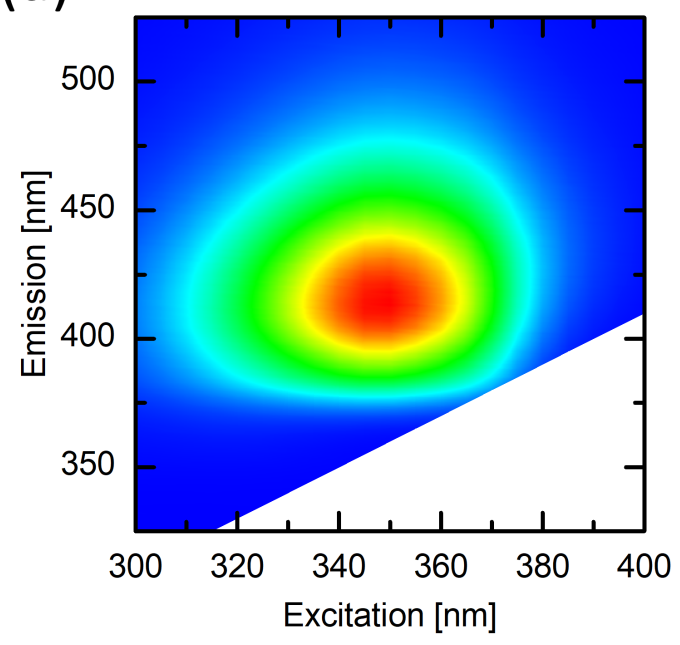

(c)

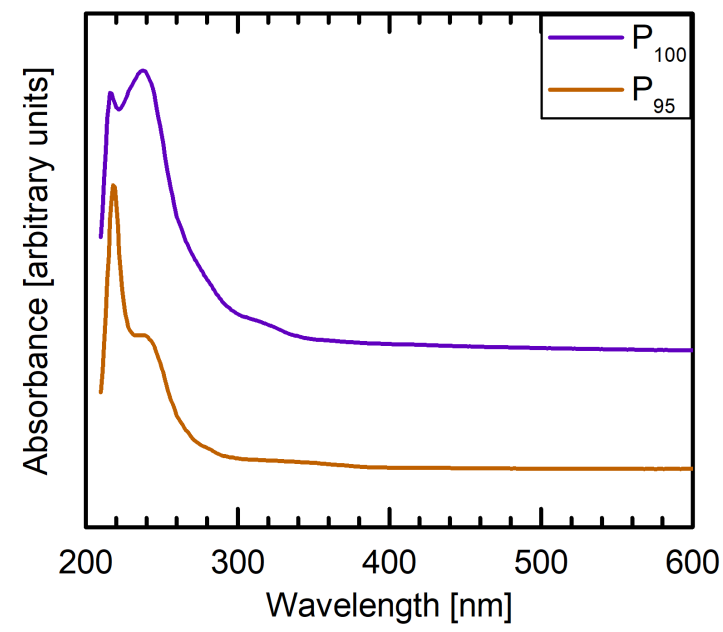

(b)

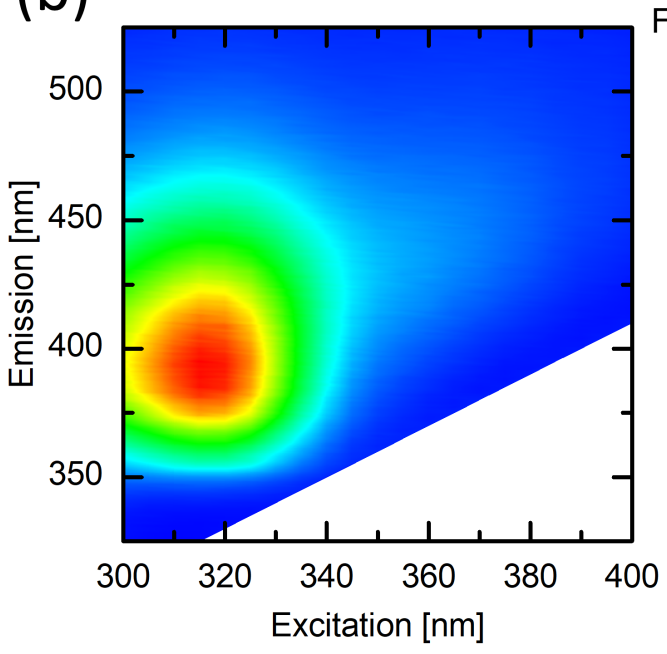

uorescence Intensity

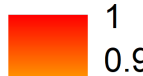

0.9

0.7

0.6

0.5

0.4

0.3

0.2

0.1

(d)

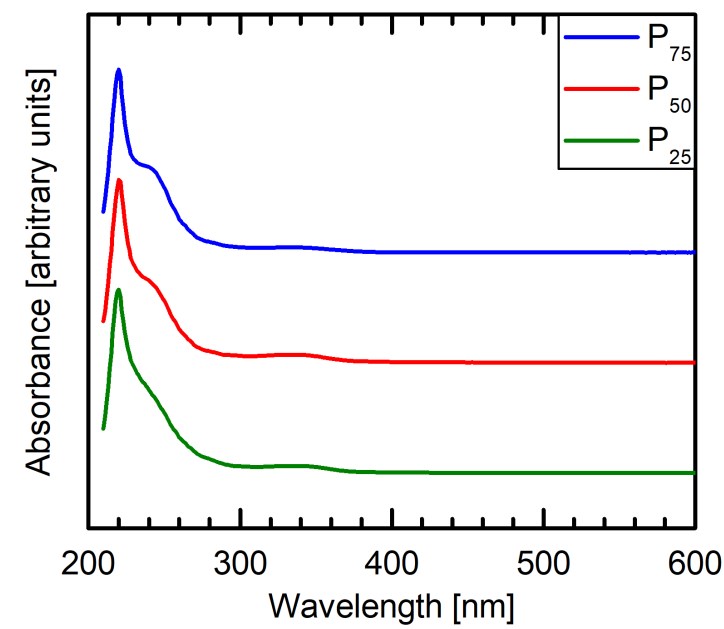

Figure 4. Fluorescence heat maps of (a) $\mathrm{P}_{95}-\mathrm{CDs}$ and (b) $\mathrm{P}_{100}-\mathrm{CDs}$ over a range of excitation and emission

322 wavelengths using an excitation and emission slit width of $3 \mathbf{~ n m}$. Absorbance spectra of (c) P95-CDs and P100-

323 CDs, and (d) $\mathbf{P}_{25}-\mathrm{CDs}$, $\mathbf{P}_{50}-\mathrm{CDs}$, and $\mathrm{P}_{75}-\mathrm{CDs}$. Fluorescence heat maps and absorbance spectra were normalized

324 to their respective maximum peaks.

The UV-Vis absorbance spectra reveal differences between $\mathrm{P}_{95}$-CDs and $\mathrm{P}_{100}$-CDs (Figure

4c). The ratio between the absorbance of the peak at $217 \mathrm{~nm}$ to the peak at $237 \mathrm{~nm}$ is $2.2 \times$ higher 
328 in $\mathrm{P}_{95}-\mathrm{CDs}$ relative to the ratio in $\mathrm{P}_{100}-\mathrm{CDs}$. A more broad-spectrum absorbance is also observed 329 in the $300-400 \mathrm{~nm}$ region. Figure $4 \mathrm{~d}$ shows the similarities in the $\mathrm{UV}-\mathrm{V}$ is spectra of $\mathrm{P}_{25}-\mathrm{CDs}, \mathrm{P}_{50-}$ $330 \mathrm{CDs}$, and $\mathrm{P}_{75}-\mathrm{CDs}$. They all share their most prominent peak at $220 \mathrm{~nm}$, a second peak at $237 \mathrm{~nm}$, 331 and a small peak at $334 \mathrm{~nm}$.

332 A partial explanation for the lower QY in $\mathrm{P}_{100}-\mathrm{CDs}$ is self-quenching. The ratio of the 333 absorbance at $430 \mathrm{~nm}$ to the absorbance at $350 \mathrm{~nm}$ is 0.27 for $\mathrm{P}_{95}-\mathrm{CDs}$, but 0.62 for $\mathrm{P}_{100}-\mathrm{CDs}$. This 334 means that a larger proportion of the fluorescence that may have been generated by $\mathrm{P}_{100}-\mathrm{CDs}$ is 335 reabsorbed by itself, effectively lowering its QY.

336 Individual fluorescence lifetimes of $\mathrm{P}_{95}-\mathrm{CDs}$ were significantly different $(\mathrm{p}<0.05)$ from $337 \mathrm{P}_{100}$-CDs. Both CDs exhibited a biexponential decay with two fluorescence lifetimes (Figure S7a). $338 \mathrm{P}_{95}$-CDs had a lifetime of $5.12 \pm 0.70 \mathrm{~ns}$ and $36.5 \pm 1.0 \mathrm{~ns}$, while $\mathrm{P}_{100}-\mathrm{CDs}$ had a lifetime of $3392.51 \pm 1.38 \mathrm{~ns}$ and $47.7 \pm 6.8 \mathrm{~ns}$.

\section{Structural Characterization of CDs}

AFM imaging (Figure 5a,b) indicates that $\mathrm{P}_{95}-\mathrm{CDs}$ have a thickness of $1.8 \pm 0.2 \mathrm{~nm}$ and a

343 diameter of $12.8 \pm 0.6 \mathrm{~nm}$. The $\mathrm{P}_{100}$-CDs are larger, with a thickness of $3.7 \pm 0.5 \mathrm{~nm}$ and a diameter 344 of $17.0 \pm 1.7 \mathrm{~nm}$. TEM data suggests smaller diameters than those obtained by AFM. TEM imaging 345 (Figure 5c,d) shows that $\mathrm{P}_{95}-\mathrm{CDs}$ have a mean diameter of $11.9 \pm 0.6 \mathrm{~nm}$, while $\mathrm{P}_{100}-\mathrm{CDs}$ have a 346 mean diameter of $7.2 \pm 0.4 \mathrm{~nm}$. Figure $\mathrm{S} 8$ shows the histogram of the size distribution for $\mathrm{P}_{95}-\mathrm{CDs}$ 347 and $\mathrm{P}_{100}-\mathrm{CDs}$ based on TEM imaging. Possible explanations for the size discrepancy between 348 AFM and TEM results are provided in the Size Analysis section of the SI. Additionally, the AFM 349 and TEM images (Figure 5) indicate that our processing and purification methods did not result in 350 any noticeable aggregation of the CDs in water. 

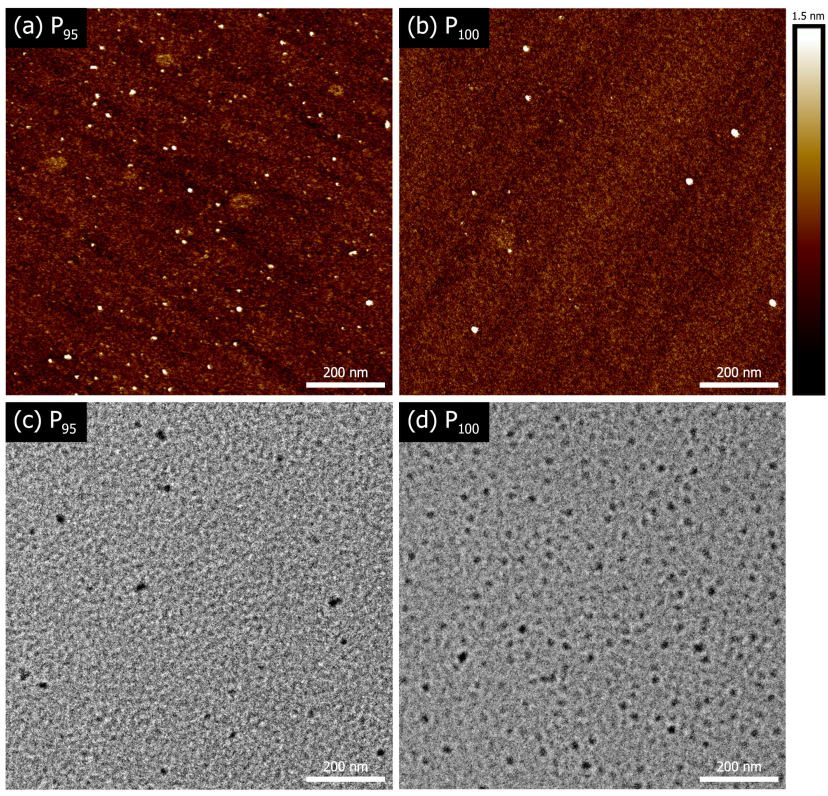

354 Figure 5. AFM images of (a) $\mathbf{P}_{95}-\mathrm{CDs}$ and (b) $\mathbf{P}_{100}$-CDs. TEM images of (c) $\mathbf{P}_{95}-\mathrm{CDs}$ and (d) $\mathbf{P}_{100}$-CDs. TEM 355 images have been cropped to match the scale of AFM images. Uncropped images can be found in Figure S9.

Although there are differences in size and thickness between $\mathrm{P}_{95}-\mathrm{CDs}$ and $\mathrm{P}_{100}-\mathrm{CDs}$, it is 358 difficult to determine if this factor played a role in the vast difference between their QYs. Chandra 359 et al. synthesized CDs from citric acid and $\left(\mathrm{NH}_{4}\right)_{2} \mathrm{HPO}_{4}$ with a size of $1.5-4 \mathrm{~nm}$, as measured by 360 TEM, and a QY of 59\%. ${ }^{53}$ This shows that it is possible to have high QYs with small CDs, making 361 it unlikely that size is the primary explanation for the difference in QY since other researchers 362 have reported smaller sizes while still having a comparable QY to $\mathrm{P}_{95}-\mathrm{CDs}{ }^{54,55}$

363 To study the structure of the CDs, Raman spectroscopy was attempted; however, the high 364 fluorescence from the CDs obscured the Raman signal (Figure S10). ${ }^{56-58}$ 
371 results are summarized in Figure 6a. Fluorescence quenching is observed by $\mathrm{Fe}^{2+}, \mathrm{Fe}^{3+}, \mathrm{Co}^{2+}, \mathrm{Pd}^{2+}$, $372 \mathrm{Cu}^{2+}, \mathrm{Ag}^{+}$, and $\mathrm{Au}^{3+}$ at $1000 \mu \mathrm{M}$; however, only $\mathrm{Fe}^{3+}$ and $\mathrm{Pd}^{2+}$ are able to completely quench the

$373 \mathrm{CD}$ fluorescence at this concentration. $\mathrm{Fe}^{3+}$ plays an important role in several biological functions

374 and an imbalance in its concentration in the body can lead to various diseases. ${ }^{66}$ Similarly, $\mathrm{Pd}^{2+}$

375 has shown toxicity. ${ }^{67}$ Of the ions tested, $\mathrm{Fe}^{3+}$ shows the greatest fluorescence quenching capability

376 (see Figure $\mathrm{S} 11$ for a comparison with $\mathrm{Pd}^{2+}$ at concentrations below $1000 \mu \mathrm{M}$ ). The fluorescence

377 intensity of the $\mathrm{P}_{95}-\mathrm{CD}$ emission spectrum decreases with increasing $\mathrm{Fe}^{3+}$ concentration (Figure

$378 \mathrm{~S} 12 \mathrm{a}$ ). Examining the fluorescence quenching capabilities of $\mathrm{Fe}^{3+}$ reveals a linear trend (Figure

$3796 \mathrm{~b})$ at $\mathrm{Fe}^{3+}$ concentrations below $50 \mu \mathrm{M}$. The limit of detection for $\mathrm{Fe}^{3+}$ is $3.5 \mu \mathrm{M}$. 

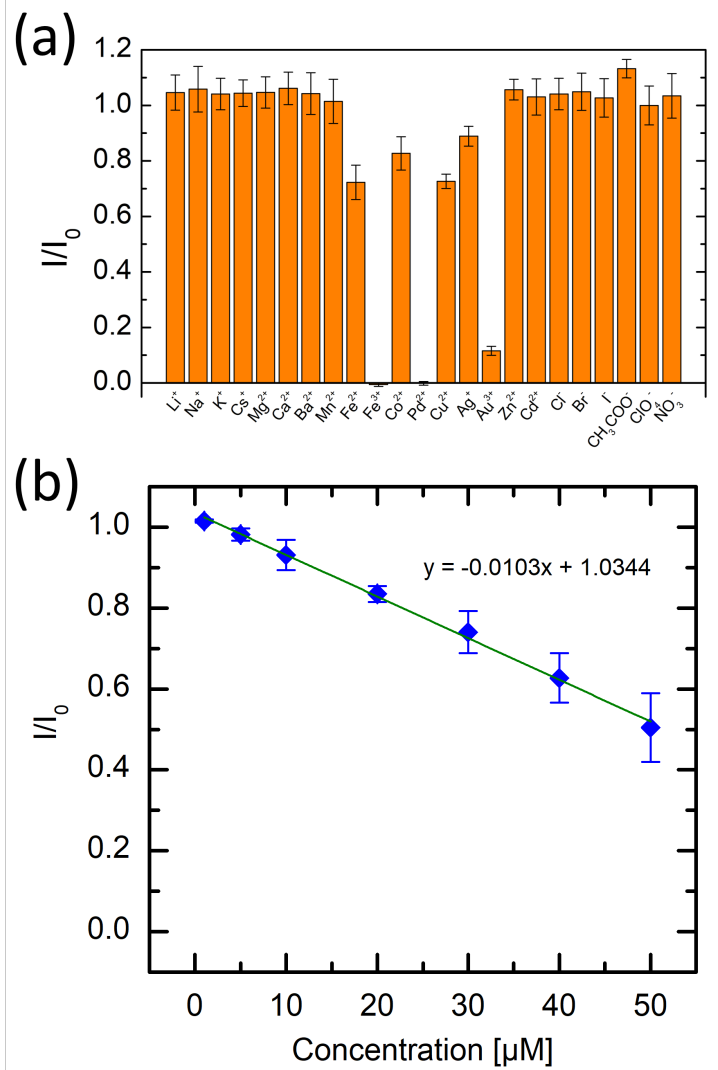

382 Figure 6. Relative fluorescence of $\mathrm{P}_{95}-\mathrm{CDs}$ exposed to a) $1000 \mu \mathrm{M}$ of various ions and b) $\mathrm{Fe}^{3+}$ at various concentrations. Error bars show 2 standard errors of the mean $(\mathrm{N}=3)$.

A new absorbance peak forms at $220 \mathrm{~nm}$ when $\mathrm{P}_{95}-\mathrm{CDs}$ are mixed with $\mathrm{Fe}^{3+}$ ions (Figure $\mathrm{S} 12 \mathrm{~b})$. Moreover, the peak absorbance of the $\mathrm{Fe}^{3+}$ solution does not overlap with the peak emission 387 spectra of $\mathrm{P}_{95}-\mathrm{CDs}$ (Figure S13). Furthermore, the fluorescence lifetime of $\mathrm{P}_{95}$-CDs remains 388 unchanged after the addition of $50 \mu \mathrm{M} \mathrm{Fe}^{3+}$ (Figure $\mathrm{S} 7 \mathrm{~b}$ ). These observations suggest that a static 389 fluorescence quenching mechanism is in effect, whereby $\mathrm{Fe}^{3+}$ ions form a complex with the $\mathrm{P}_{95^{-}}$ 390 CDs. $^{61}$ Zhang et al. suggested that the presence of phenolic hydroxyl groups may explain the 391 fluorescence quenching of $\mathrm{Fe}^{3+} .{ }^{68}$ The fact that $\mathrm{Fe}^{2+}$ did not quench fluorescence while $\mathrm{Fe}^{3+}$ did, 392 has been used creatively by other researchers to detect other oxidizing agents. For example, Qian 393 et al. prepared a mixture of CDs with $\mathrm{Fe}^{2+}$, which upon exposure to $\mathrm{H}_{2} \mathrm{O}_{2}$, would get oxidized into 
$394 \mathrm{Fe}^{3+}$ and quench fluorescence, effectively creating an $\mathrm{H}_{2} \mathrm{O}_{2}$ sensor. ${ }^{69}$ Consequently, $\mathrm{Fe}^{3+}$ sensing 395 CDs can find application by either detecting the presence of $\mathrm{Fe}^{3+}$ directly, or through the oxidation 396 of $\mathrm{Fe}^{2+}$ to the fluorescence quenching $\mathrm{Fe}^{3+}$.

\section{Conclusions}

400 ratios achieving a QY as high as $65 \%$ with a peak excitation/emission of $350 / 413 \mathrm{~nm}$. The initial

401 addition of phenylalanine to citric acid resulted in a great increase in QY, whereas adding more 402 phenylalanine increased QY at a more gradual rate. Phenylalanine reacts with citric acid in a 1:1 403 molar ratio as the phenylalanine mole fraction approaches zero. $\mathrm{P}_{25}-\mathrm{CDs}, \mathrm{P}_{50}-\mathrm{CDs}$, and $\mathrm{P}_{75}$-CDs 404 had comparable QYs, (N:C) $)_{\mathrm{CD}}$, and FTIR, fluorescence, and UV-Vis spectra despite being 405 synthesized over a large range of reactant ratios. This information could be useful for the 406 optimization of large-scale CD synthesis, e.g. synthesis at, or near, the stoichiometric 2:1 407 phenylalanine to citric acid ratio could allow for the recycling of the dialysis buffer to produce 408 more CDs. It was found that the QY of CDs was correlated to the $(\mathrm{O}: \mathrm{C})_{\mathrm{CD}}$ and the relative amount 409 of $\mathrm{COOH}$ oxygen, whereby a reduction in these components resulted in an increase in QY. This 410 phenomenon explained why $\mathrm{P}_{95}$-CDs had a considerably larger QY than $\mathrm{P}_{100}-\mathrm{CDs}$, despite both 411 CDs having the same $(\mathrm{N}: \mathrm{C})_{\mathrm{CD}}$, revealing that nitrogen doping alone is insufficient to increase $\mathrm{QY}$. $412 \mathrm{Fe}^{3+}$ ions exhibited static fluorescence quenching of $\mathrm{P}_{95}$-CDs leading to a limit of detection of 3.5 $413 \mu \mathrm{M}$. 


\section{Acknowledgements}

The authors acknowledge funding from the Natural Sciences and Engineering Research

417 Council of Canada, the Canada Research Chairs Program, and the Canada Foundation for

418 Innovation. S. Chahal acknowledges NSERC for a PGS D scholarship, McGill University for a

419 MEDA fellowship, and the support of the EUL fund in the Department of Chemical Engineering.

420 N. Yousefi acknowledges McGill University for a MEDA fellowship, and the support of the EUL

421 fund in the Department of Chemical Engineering. We also thank M. Ramkaran for her help in 422 acquiring AFM images, as well as D. Liu and S. K. Sears for their help in acquiring TEM images.

424 Present Address

425 Current affiliation of Nariman Yousefi: Department of Chemical Engineering, Ryerson 426 University, 350 Victoria Street, Toronto, Ontario M5B 2K3, Canada

\section{ASSOCIATED CONTENT}

\section{Supporting Information}

430 The Supporting Information is available free of charge at https://pubs.acs.org/doi/

List of synthesis conditions. Elemental composition of CDs from XPS. Detailed breakdown of XPS peak deconvolutions. Parameters for multiple linear regression analysis. Graphical representations of XPS peak deconvolutions. Different normalization of FTIR spectra. Complete FTIR data of CDs and reactants. Principal component analysis of XPS data of CDs. Fluorescence heat maps of $\mathrm{P}_{25}-\mathrm{CDs}, \mathrm{P}_{50}-\mathrm{CDs}$, and $\mathrm{P}_{75}-\mathrm{CDs}$. 
of CD size distributions from TEM. Uncropped TEM images. Raman spectroscopy showing fluorescence interference from CDs. Fluorescence quenching of $\mathrm{Fe}^{3+}$ and $\mathrm{Pd}^{2+}$. Fluorescence and UV-Vis absorbance spectra regarding $\mathrm{Fe}^{3+}$ sensing. Detailed XPS, FTIR, and size analyses.

441 
443 1. Xu, X.; Ray, R.; Gu, Y.; Ploehn, H. J.; Gearheart, L.; Raker, K.; Scrivens, W. A., 444 Electrophoretic Analysis and Purification of Fluorescent Single-Walled Carbon Nanotube 445 Fragments. J. Am. Chem. Soc. 2004, 126 (40), 12736-12737. doi:10.1021/ja040082h.

$446 \quad 2 . \quad$ Peng, H.; Travas-Sejdic, J., Simple Aqueous Solution Route to Luminescent Carbogenic Dots from Carbohydrates. Chem. Mater. 2009, 21 (23), 5563-5565. doi:10.1021/cm901593y. 3. Zhang, X.; Wang, H.; Wang, H.; Zhang, Q.; Xie, J.; Tian, Y.; Wang, J.; Xie, Y., SingleLayered Graphitic-C3N4 Quantum Dots for Two-Photon Fluorescence Imaging of Cellular Nucleus. Adv. Mater. 2014, 26 (26), 4438-4443. doi:10.1002/adma.201400111.

451 4. Zhao, Q.-L.; Zhang, Z.-L.; Huang, B.-H.; Peng, J.; Zhang, M.; Pang, D.-W., Facile preparation of low cytotoxicity fluorescent carbon nanocrystals by electrooxidation of graphite. Chem. Commun. 2008, (41), 5116-5118. doi:10.1039/B812420E.

5. Yadav, P. K.; Singh, V. K.; Chandra, S.; Bano, D.; Kumar, V.; Talat, M.; Hasan, S. H., Green Synthesis of Fluorescent Carbon Quantum Dots from Azadirachta indica Leaves and Their Peroxidase-Mimetic Activity for the Detection of $\mathrm{H} 2 \mathrm{O} 2$ and Ascorbic Acid in Common Fresh Fruits. ACS Biomater. Sci. Eng. 2019, 5 (2), 623-632. doi:10.1021/acsbiomaterials.8b01528. Hamers, R. J.; Rosenzweig, Z.; Fairbrother, D. H.; Orr, G.; Haynes, C. L., Malic Acid Carbon Dots: From Super-resolution Live-Cell Imaging to Highly Efficient Separation. ACS Nano 2018, 12 (6), 5741-5752. doi:10.1021/acsnano.8b01619. of Fluorescent Carbon Dots from Gynostemma for Bioimaging and Antioxidant in Zebrafish. ACS Appl. Mater. Interfaces 2019, 11 (10), 9832-9840. doi:10.1021/acsami.9b00074. 8. Derfus, A. M.; Chan, W. C. W.; Bhatia, S. N., Probing the Cytotoxicity of Semiconductor Quantum Dots. Nano Lett. 2004, 4 (1), 11-18. doi:10.1021/nl0347334. B.; Hoet, P. H. M., Acute Toxicity and Prothrombotic Effects of Quantum Dots: Impact of Surface Charge. Environ. Health Perspect. 2008, 116 (12), 1607-1613. doi:10.1289/ehp.11566. 10. Kirchner, C.; Liedl, T.; Kudera, S.; Pellegrino, T.; Muñoz Javier, A.; Gaub, H. E.; Stölzle, S.; Fertig, N.; Parak, W. J., Cytotoxicity of Colloidal CdSe and CdSe/ZnS Nanoparticles. Nano Lett. 2005, 5 (2), 331-338. doi:10.1021/n1047996m.

11. Yang, S.-T.; Wang, X.; Wang, H.; Lu, F.; Luo, P. G.; Cao, L.; Meziani, M. J.; Liu, J.H.; Liu, Y.; Chen, M.; Huang, Y.; Sun, Y.-P., Carbon Dots as Nontoxic and High-Performance Fluorescence Imaging Agents. J. Phys. Chem. C 2009, 113 (42), 18110-18114. doi:10.1021/jp9085969.

12. Wei, Z.; Wang, B.; Liu, Y.; Liu, Z.; Zhang, H.; Zhang, S.; Chang, J.; Lu, S., Green synthesis of nitrogen and sulfur co-doped carbon dots from Allium fistulosum for cell imaging. New J. Chem. 2019, 43 (2), 718-723. doi:10.1039/C8NJ05783D.

480 13. Pandey, S.; Mewada, A.; Thakur, M.; Tank, A.; Sharon, M., Cysteamine hydrochloride 481 protected carbon dots as a vehicle for the efficient release of the anti-schizophrenic drug haloperidol. $R S C A d v$. 2013, 3 (48), 26290-26296. doi:10.1039/C3RA42139B.

14. Gong, N.; Ma, X.; Ye, X.; Zhou, Q.; Chen, X.; Tan, X.; Yao, S.; Huo, S.; Zhang, T.; 486 Chen, S.; Teng, X.; Hu, X.; Yu, J.; Gan, Y.; Jiang, H.; Li, J.; Liang, X.-J., Carbon-dot-supported atomically dispersed gold as a mitochondrial oxidative stress amplifier for cancer treatment. Nat. Nanotechnol. 2019, 14 (4), 379-387. doi:10.1038/s41565-019-0373-6. 
15. Ensafi, A. A.; Sefat, S. H.; Kazemifard, N.; Rezaei, B., An optical sensor based on inner filter effect using green synthesized carbon dots and $\mathrm{Cu}(\mathrm{II})$ for selective and sensitive penicillamine determination. J. Iran. Chem. Soc. 2019, 16 (2), 355-363. doi:10.1007/s13738-018490 1518-5.

491 16. Bhatt, S.; Bhatt, M.; Kumar, A.; Vyas, G.; Gajaria, T.; Paul, P., Green route for synthesis of multifunctional fluorescent carbon dots from Tulsi leaves and its application as Cr(VI) sensors, bio-imaging and patterning agents. Colloids Surf., $B$ 2018, 167, 126-133. doi:10.1016/j.colsurfb.2018.04.008.

17. Bhunia, S. K.; Nandi, S.; Shikler, R.; Jelinek, R., Tuneable light-emitting carbondot/polymer flexible films prepared through one-pot synthesis. Nanoscale 2016, 8 (6), 3400-3406. doi:10.1039/C5NR08400H.

498 18. Xu, J.; Miao, Y.; Zheng, J.; Yang, Y.; Liu, X., Ultrahigh Brightness Carbon Dot-Based Blue Electroluminescent LEDs by Host-Guest Energy Transfer Emission Mechanism. Adv. Opt.

19. Jayanthi, M.; Megarajan, S.; Subramaniyan, S. B.; Kamlekar, R. K.; Veerappan, A., A convenient green method to synthesize luminescent carbon dots from edible carrot and its application in bioimaging and preparation of nanocatalyst. J. Mol. Liq. 2019, 278, 175-182. doi:10.1016/j.molliq.2019.01.070.

20. Dao, V.-D.; Kim, P.; Baek, S.; Larina, L. L.; Yong, K.; Ryoo, R.; Ko, S. H.; Choi, H.S., Facile synthesis of carbon dot-Au nanoraspberries and their application as high-performance counter electrodes in quantum dot-sensitized solar cells. Carbon 2016, 96, 139-144. doi:10.1016/j.carbon.2015.09.023.

21. Kumar, D.; Jain, V. K.; Shanker, G.; Srivastava, A., Citric acid production by solid state fermentation using sugarcane bagasse. Process Biochem. 2003, 38 (12), 1731-1738. doi:10.1016/S0032-9592(02)00252-2.

22. Liao, J.; Cheng, Z.; Zhou, L., Nitrogen-Doping Enhanced Fluorescent Carbon Dots: Green Synthesis and Their Applications for Bioimaging and Label-Free Detection of Au3+ Ions. ACS Sustainable Chem. Eng. 2016, 4 (6), 3053-3061. doi:10.1021/acssuschemeng.6b00018.

23. Ding, D.; Liu, Y.; Xu, Y.; Zheng, P.; Li, H.; Zhang, D.; Sun, J., Improving the Production of L-Phenylalanine by Identifying Key Enzymes Through Multi-Enzyme Reaction System in Vitro. Sci. Rep. 2016, 6, 32208 (1-11). doi:10.1038/srep32208.

24. Gerigk, M.; Bujnicki, R.; Ganpo-Nkwenkwa, E.; Bongaerts, J.; Sprenger, G.; Takors, R., Process control for enhanced L-phenylalanine production using different recombinant Escherichia coli strains. Biotechnol. Bioeng. 2002, 80 (7), 746-754. doi:10.1002/bit.10428.

25. Yang, J.; Chen, W.; Liu, X.; Zhang, Y.; Bai, Y., Hydrothermal synthesis and photoluminescent mechanistic investigation of highly fluorescent nitrogen doped carbon dots from amino acids. Mater. Res. Bull. 2017, 89, 26-32. doi:10.1016/j.materresbull.2017.01.013.

26. Lijuan, K.; Yongqiang, Y.; Ruiyi, L.; Zaijun, L., Phenylalanine-functionalized graphene quantum dot-silicon nanoparticle composite as an anode material for lithium ion batteries with largely enhanced electrochemical performance. Electrochim. Acta 2016, 198, 144-155. doi:10.1016/j.electacta.2016.03.034.

27. Shen, P.; Xia, Y., Synthesis-Modification Integration: One-Step Fabrication of Boronic Acid Functionalized Carbon Dots for Fluorescent Blood Sugar Sensing. Anal. Chem. 2014, 86 (11), 5323-5329. doi:10.1021/ac5001338. 
28. Wang, Z.; Fu, B.; Zou, S.; Duan, B.; Chang, C.; Yang, B.; Zhou, X.; Zhang, L., Facile construction of carbon dots via acid catalytic hydrothermal method and their application for target imaging of cancer cells. Nano Res. 2016, 9 (1), 214-223. doi:10.1007/s12274-016-0992-2.

29. Williams, A. T. R.; Winfield, S. A.; Miller, J. N., Relative fluorescence quantum yields using a computer-controlled luminescence spectrometer. Analyst 1983, 108 (1290), 1067-1071. doi:10.1039/AN9830801067.

30. Brouwer, A. M., Standards for photoluminescence quantum yield measurements in solution (IUPAC Technical Report). Pure Appl. Chem. 2011, 83 (12), 2213-2228. doi:10.1351/PAC-REP-10-09-31.

31. Yarur, F.; Macairan, J.-R.; Naccache, R., Ratiometric detection of heavy metal ions using fluorescent carbon dots. Environ. Sci.: Nano 2019, 6 (4), 1121-1130. doi:10.1039/C8EN01418C. 32. Solomons, T. W. G.; Fryhle, C. B., Organic Chemistry. 10 ed.; John Wiley \& Sons, Inc.: Hoboken, New Jersey, 2011.

33. Zhang, Z.; Chen, J.; Duan, Y.; Liu, W.; Li, D.; Yan, Z.; Yang, K., Highly luminescent nitrogen-doped carbon dots for simultaneous determination of chlortetracycline and sulfasalazine. Lumin. 2018, 33 (2), 318-325. doi:10.1002/bio.3416.

34. Miao, X.; Qu, D.; Yang, D.; Nie, B.; Zhao, Y.; Fan, H.; Sun, Z., Synthesis of Carbon Dots with Multiple Color Emission by Controlled Graphitization and Surface Functionalization. Adv. Mater. 2018, 30 (1), 1704740 (1-8). doi:10.1002/adma.201704740.

35. Ogi, T.; Aishima, K.; Permatasari, F. A.; Iskandar, F.; Tanabe, E.; Okuyama, K., Kinetics of nitrogen-doped carbon dot formation via hydrothermal synthesis. New J. Chem. 2016, 40 (6), 5555-5561. doi:10.1039/C6NJ00009F.

36. Hou, J.; Wang, W.; Zhou, T.; Wang, B.; Li, H.; Ding, L., Synthesis and formation mechanistic investigation of nitrogen-doped carbon dots with high quantum yields and yellowishgreen fluorescence. Nanoscale 2016, 8 (21), 11185-11193. doi:10.1039/C6NR02701F.

37. Zheng, C.; An, X.; Gong, J., Novel pH sensitive N-doped carbon dots with both long fluorescence lifetime and high quantum yield. RSC $A d v$. 2015, 5 (41), 32319-32322. doi:10.1039/C5RA01986A.

38. Qu, D.; Zheng, M.; Zhang, L.; Zhao, H.; Xie, Z.; Jing, X.; Haddad, R. E.; Fan, H.; Sun, Z., Formation mechanism and optimization of highly luminescent $\mathrm{N}$-doped graphene quantum dots. Sci. Rep. 2014, 4, 5294 (1-9). doi:10.1038/srep05294.

39. Zhu, S.; Meng, Q.; Wang, L.; Zhang, J.; Song, Y.; Jin, H.; Zhang, K.; Sun, H.; Wang, H.; Yang, B., Highly Photoluminescent Carbon Dots for Multicolor Patterning, Sensors, and Bioimaging. Angew. Chem., Int. Ed. 2013, 52 (14), 3953-3957. doi:10.1002/anie.201300519.

40. Guo, Y.; Wang, Z.; Shao, H.; Jiang, X., Hydrothermal synthesis of highly fluorescent carbon nanoparticles from sodium citrate and their use for the detection of mercury ions. Carbon 2013, 52, 583-589. doi:10.1016/j.carbon.2012.10.028.

41. Permatasari, F. A.; Aimon, A. H.; Iskandar, F.; Ogi, T.; Okuyama, K., Role of C-N Configurations in the Photoluminescence of Graphene Quantum Dots Synthesized by a Hydrothermal Route. Sci. Rep. 2016, 6, 21042 (1-8). doi:10.1038/srep21042.

42. Tyagi, A.; Tripathi, K. M.; Singh, N.; Choudhary, S.; Gupta, R. K., Green synthesis of carbon quantum dots from lemon peel waste: applications in sensing and photocatalysis. RSC Adv. 2016, 6 (76), 72423-72432. doi:10.1039/C6RA10488F.

43. Bandi, R.; Gangapuram, B. R.; Dadigala, R.; Eslavath, R.; Singh, S. S.; Guttena, V., Facile and green synthesis of fluorescent carbon dots from onion waste and their potential 
applications as sensor and multicolour imaging agents. RSC Adv. 2016, 6 (34), 28633-28639. doi:10.1039/C6RA01669C.

44. Atchudan, R.; Edison, T. N. J. I.; Sethuraman, M. G.; Lee, Y. R., Efficient synthesis of highly fluorescent nitrogen-doped carbon dots for cell imaging using unripe fruit extract of Prunus mume. Appl. Surf. Sci. 2016, 384, 432-441. doi:10.1016/j.apsusc.2016.05.054. green synthesis of nitrogen-doped carbon nanoparticles as fluorescent probes for mercury ions. RSC Adv. 2013, 3 (44), 21691-21696. doi:10.1039/C3RA43452D.

46. Zhu, C.; Zhai, J.; Dong, S., Bifunctional fluorescent carbon nanodots: green synthesis via soy milk and application as metal-free electrocatalysts for oxygen reduction. Chem. Commun. 2012, 48 (75), 9367-9369. doi:10.1039/C2CC33844K.

47. Li, Q.; Chen, B.; Xing, B., Aggregation Kinetics and Self-Assembly Mechanisms of Graphene Quantum Dots in Aqueous Solutions: Cooperative Effects of $\mathrm{pH}$ and Electrolytes. Environ. Sci. Technol. 2017, 51 (3), 1364-1376. doi:10.1021/acs.est.6b04178. M., Preparation and characterization of polypropylene-graft-thermally reduced graphite oxide with an improved compatibility with polypropylene-based nanocomposite. Nanoscale 2011, 3 (4), 1516-1522. doi:10.1039/C0NR00981D.

49. Samantara, A. K.; Chandra Sahu, S.; Ghosh, A.; Jena, B. K., Sandwiched graphene with nitrogen, sulphur co-doped CQDs: an efficient metal-free material for energy storage and conversion applications. J. Mater. Chem. A 2015, 3 (33), 16961-16970. doi:10.1039/C5TA03376D.

598 50. Oh, Y. J.; Yoo, J. J.; Kim, Y. I.; Yoon, J. K.; Yoon, H. N.; Kim, J.-H.; Park, S. B., Oxygen functional groups and electrochemical capacitive behavior of incompletely reduced 600 graphene oxides as a thin-film electrode of supercapacitor. Electrochim. Acta 2014, 116, 118-128. 601 doi:10.1016/j.electacta.2013.11.040.

602 51. Błoński, P.; Tuček, J.; Sofer, Z.; Mazánek, V.; Petr, M.; Pumera, M.; Otyepka, M.; 603 Zbořil, R., Doping with Graphitic Nitrogen Triggers Ferromagnetism in Graphene. J. Am. Chem.

604

605

606

607

608 Soc. 2017, 139 (8), 3171-3180. doi:10.1021/jacs.6b12934.

52. Zhang, W.; Liu, Y.; Meng, X.; Ding, T.; Xu, Y.; Xu, H.; Ren, Y.; Liu, B.; Huang, J.; Yang, J.; Fang, X., Graphenol defects induced blue emission enhancement in chemically reduced graphene quantum dots. Phys. Chem. Chem. Phys. 2015, 17 (34), 22361-22366. doi:10.1039/C5CP03434E.

53. Chandra, S.; Laha, D.; Pramanik, A.; Ray Chowdhuri, A.; Karmakar, P.; Sahu, S. K., Synthesis of highly fluorescent nitrogen and phosphorus doped carbon dots for the detection of $\mathrm{Fe} 3+$ ions in cancer cells. Lumin. 2016, 31 (1), 81-87. doi:10.1002/bio.2927.

54. Dong, Y.; Wang, R.; Li, H.; Shao, J.; Chi, Y.; Lin, X.; Chen, G., Polyaminefunctionalized carbon quantum dots for chemical sensing. Carbon 2012, 50 (8), 2810-2815. doi:10.1016/j.carbon.2012.02.046.

55. Yang, Y.; Cui, J.; Zheng, M.; Hu, C.; Tan, S.; Xiao, Y.; Yang, Q.; Liu, Y., One-step synthesis of amino-functionalized fluorescent carbon nanoparticles by hydrothermal carbonization of chitosan. Chem. Commun. 2012, 48 (3), 380-382. doi:10.1039/C1CC15678K.

56. Yang, Z.; Xu, M.; Liu, Y.; He, F.; Gao, F.; Su, Y.; Wei, H.; Zhang, Y., Nitrogen-doped, carbon-rich, highly photoluminescent carbon dots from ammonium citrate. Nanoscale 2014, 6 (3), 1890-1895. doi:10.1039/C3NR05380F. 
57. Xu, M.; He, G.; Li, Z.; He, F.; Gao, F.; Su, Y.; Zhang, L.; Yang, Z.; Zhang, Y., A green heterogeneous synthesis of $\mathrm{N}$-doped carbon dots and their photoluminescence applications in solid and aqueous states. Nanoscale 2014, 6 (17), 10307-10315. doi:10.1039/C4NR02792B. 58. Bourlinos, A. B.; Stassinopoulos, A.; Anglos, D.; Zboril, R.; Karakassides, M.; Giannelis, E. P., Surface Functionalized Carbogenic Quantum Dots. Small 2008, 4 (4), 455-458. doi:10.1002/smll.200700578.

59. $\quad$ Bhamore, J. R.; Jha, S.; Singhal, R. K.; Park, T. J.; Kailasa, S. K., Facile green synthesis of carbon dots from Pyrus pyrifolia fruit for assaying of Al3+ ion via chelation enhanced fluorescence mechanism. J. Mol. Liq. 2018, 264, 9-16. doi:10.1016/j.molliq.2018.05.041.

60. Radhakrishnan, K.; Panneerselvam, P., Green synthesis of surface-passivated carbon dots from the prickly pear cactus as a fluorescent probe for the dual detection of arsenic(iii) and hypochlorite ions from drinking water. $R S C \quad A d v . \quad \mathbf{2 0 1 8}, \quad 8$ (53), 30455-30467. doi:10.1039/C8RA05861J.

61. Ramanan, V.; Siddaiah, B.; Raji, K.; Ramamurthy, P., Green Synthesis of Multifunctionalized, Nitrogen-Doped, Highly Fluorescent Carbon Dots from Waste Expanded Polystyrene and Its Application in the Fluorimetric Detection of Au3+ Ions in Aqueous Media. ACS Sustainable Chem. Eng. 2018, 6 (2), 1627-1638. doi:10.1021/acssuschemeng.7b02852. 62. Murugan, N.; Prakash, M.; Jayakumar, M.; Sundaramurthy, A.; Sundramoorthy, A. K., Green synthesis of fluorescent carbon quantum dots from Eleusine coracana and their application as a fluorescence 'turn-off' sensor probe for selective detection of Cu2+. Appl. Surf. Sci. 2019, 476, 468-480. doi:10.1016/j.apsusc.2019.01.090.

63. Rooj, B.; Dutta, A.; Islam, S.; Mandal, U., Green Synthesized Carbon Quantum Dots from Polianthes tuberose L. Petals for Copper (II) and Iron (II) Detection. J. Fluoresc. 2018, 28 (5), 1261-1267. doi:10.1007/s10895-018-2292-6.

64. Ramanan, V.; Subray, S. H.; Ramamurthy, P., A green synthesis of highly luminescent carbon dots from itaconic acid and their application as an efficient sensor for $\mathrm{Fe} 3+$ ions in aqueous medium. New J. Chem. 2018, 42 (11), 8933-8942. doi:10.1039/C8NJ00813B.

65. Pourreza, N.; Ghomi, M., Green synthesized carbon quantum dots from Prosopis juliflora leaves as a dual off-on fluorescence probe for sensing mercury (II) and chemet drug. Mater. Sci. Eng., C 2019, 98, 887-896. doi:10.1016/j.msec.2018.12.141.

66. Hu, Y.; Zhao, F.; Hu, S.; Dong, Y.; Li, D.; Su, Z., A novel turn-on colorimetric and fluorescent sensor for Fe3+ and its application in living cells. J. Photochem. Photobiol., A 2017, 332, 351-356. doi:10.1016/j.jphotochem.2016.09.006.

67. Wataha, J. C.; Hanks, C. T., Biological effects of palladium and risk of using palladium in dental casting alloys. J. Oral Rehabil. 1996, 23 (5), 309-320. doi:10.1111/j.13652842.1996.tb00858.x.

68. Zhang, Y.-L.; Wang, L.; Zhang, H.-C.; Liu, Y.; Wang, H.-Y.; Kang, Z.-H.; Lee, S.-T., Graphitic carbon quantum dots as a fluorescent sensing platform for highly efficient detection of Fe3+ ions. RSC Adv. 2013, 3 (11), 3733-3738. doi:10.1039/C3RA23410J.

69. Qian, Z.; Ma, J.; Shan, X.; Feng, H.; Shao, L.; Chen, J., Highly Luminescent N-Doped Carbon Quantum Dots as an Effective Multifunctional Fluorescence Sensing Platform. Chem.: Eur. J. 2014, 20 (8), 2254-2263. doi:10.1002/chem.201304374. 


\section{TOC/Abstract Graphic (For Table of Contents Use Only)}

666

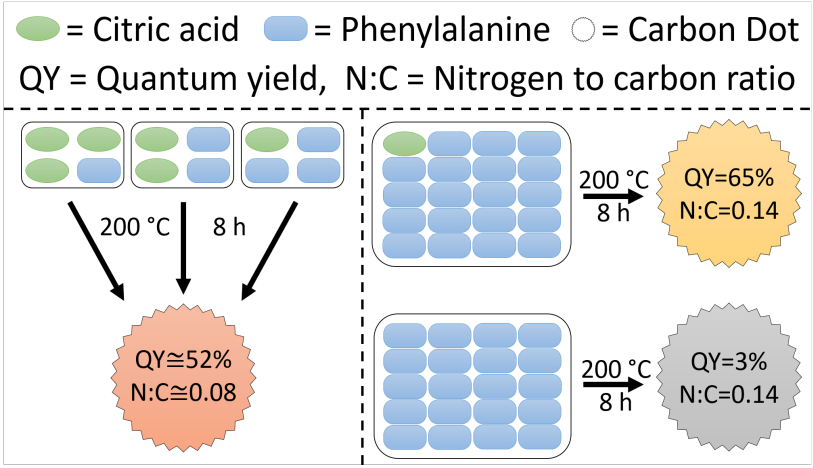

667

668 Synopsis

669

This work reveals a stoichiometric ratio for producing high quantum yield carbon dots that

670 can be useful for reducing reactant waste during large-scale production.

671 